\title{
AS MISERICÓRDIAS PORTUGUESAS ENQUANTO PALCOS DE SOCIABILIDADES NO SÉCULO XVIII
}

\author{
The Portuguese Misericórdias as places of \\ socialisation in the $18^{\text {th }}$ century
}

Maria Marta Lobo de Araújo*

\section{RESUMO}

O presente trabalho estuda as Misericórdias enquanto palcos de sociabilidades no século XVIII, destacando os momentos de encontro e de convivialidade entre os irmãos e entre estes e a comunidade. Escolhemos três momentos: as eleições, as cerimónias da semana santa e os enterros e analisamos as sociabilidades criadas pelas Misericórdias em cada um deles.

Os espaços de sociabilidade criados por estas confrarias, além de reforçarem a identidade de cada um dos seus membros, fomentavam a coesão de grupo e engrandeciam a instituição promotora.

Palavras-chave: Misericórdias; sociabilidades; irmãos.

\begin{abstract}
This paper aims to study the Misericórdias as places of socialisation in the eighteenth century Portugal, focusing on the moments of gathering between brothers and between brothers and the community.

I have chosen three particular moments: the elections, the Holy Week ceremonies and the funerals, and analysed the social relations promoted by the Misericórdias in each one of them.

The spaces of sociability created by these confraternities (the Misericórdias), apart from reinforcing its members' identity, promoted the group's cohesion and enhanced the institution.
\end{abstract}

Key-words: Misericórdias; sociabilities; brothers.

" Professora auxiliar da Universidade do Minho, Portugal. Instituto de Ciências Sociais. Campus de Gualtar - Braga - Portugal. 4710-057. Telefone: 253604280. E-mail: martalobo@ ics.uminho.pt. 
Universos masculinos, as Misericórdias eram constituídas por irmãos nobres e oficiais e operavam com numerus clausus. Nem todos os que desejavam acediam a estas confrarias de elite, ficando-se por pertencer a outras irmandades menos cotadas no ranking destas associações. O ingresso numa Misericórdia dava resposta a anseios espirituais e de caridade ao próximo, mas satisfazia ao mesmo tempo aspirações sociais e até políticas $^{1}$.

O compromisso da Misericórdia de Lisboa e os compromissos que algumas Santas Casas reformaram ou criaram estipulavam alguns momentos de sociabilidade. Outros foram posteriormente criados a partir de legados instituídos e outros ainda foram fundados pelas próprias Misericórdias. Ou seja, estas confrarias reconheciam a necessidade de manifestações rituais que estreitavam laços de fraternidade, servindo de pretexto para encontro e convívio dos que as compunham. Promoviam também oportunidades que envolviam a comunidade. As Misericórdias possuíam momentos de convivialidade especialmente vocacionados para os confrades, mas também actividades mais voltadas para o exterior, que agregavam a comunidade em que estavam inseridas.

As Misericórdias foram ao longo da Idade Moderna palcos de sociabilidades, promotoras de laços fraternais e estreitamento de relações entre os seus membros e entre estes e a comunidade. $\mathrm{O}$ presente trabalho pretende estudar estas confrarias enquanto lugares de sociabilidades ao longo do século XVIII. Escolhemos para análise alguns momentos que reputamos de grande significado para a vida destas instituições e que ficaram marcados pela intensidade com que eram vividos pelos irmãos e pela participação das pessoas exteriores nesses actos: as eleições, as festas, os jantares, as procissões, as esmolas aos pobres e os enterros.

Segundo o compromisso da Misericórdia de Lisboa de 1618, os irmãos eram obrigados a comparecer na confraria cinco vezes no ano: dia da Visitação de Nossa Senhora (para elegerem a Mesa), dia de S. Lourenço (para escolherem a Junta), dia de Todos os Santos (para irem em procissão à forca buscar os ossos dos padecentes), dia de S. Martinho (para participa-

1 Leia-se para esta matéria, MESGRAVIS, Laima. A Santa Casa da Misericórdia de S. Paulo (1599?-1884). São Paulo: Conselho Estadual de Cultura, 1976, p. 45. 
rem no ofício pela alma dos irmãos defuntos) e quinta-feira maior (para integrarem a procissão das Endoenças) ${ }^{2}$.

Todas estas ocasiões eram marcadas por actos religiosos a que os irmãos assistiam e, em algumas Misericórdias, aproveitava-se ainda o momento para se realizarem cabidos gerais ${ }^{3}$. Todos os actos que agregavam os confrades e diziam respeito exclusivamente aos seus membros ocasionavam momentos de sociabilidade masculina, restrita aos que as compunham.

Para além do fim específico a que se destinavam, estes encontros serviam para os confrades conversarem, conhecerem os novos membros, analisarem assuntos em comum e até discordarem.

\section{As eleições}

As eleições das Misericórdias realizavam-se no dia dois de julho, data em que se comemora a visitação de Nossa Senhora a sua prima Santa Isabel. Neste dia, os irmãos deviam comparecer na confraria para escolher os seus corpos gerentes. Tratava-se apenas da eleição da Mesa, já que a Junta ou Definitório se elegia a 10 de agosto, como já referimos.

A eleição da Mesa era precedida de uma missa e estendia-se por dois dias. $\mathrm{O}$ acto desenrolava-se dentro da igreja e obedecia a um ritual descrito no compromisso. Depois de lido o capítulo referente ao acto eleitoral pelo capelão, os irmãos faziam juramento sobre os Santos Evangelhos e prometiam "votar só nas pessoas, que segundo Deos e a sua consciencia lhe parecerem mais acomodadas, e dignas de serem Eleitores dos officiais que hão de servir o anno seguinte" ${ }^{4}$ e escolhiam 10 irmãos. Estavam estatutariamente impedidos de serem eleitores os irmãos que tivessem ser-

2 COMPROMISSO da Misericórdia de Lisboa. Lisboa: Pedro Craesbeeck, 1619, p. 6.

3 Os cabidos gerais eram reuniões alargadas a toda a confraria. Nestas assembleias de irmãos discutiam-se normalmente assuntos importantes, que posteriormente transitavam para a Mesa e o Definitório. Acerca das assembleias de irmãos nestas confrarias consulte-se para a Misericórdia de Lisboa CORREIA Fernando da Silva. A Misericórdia de Lisboa. A Medicina Contemporânea, n. 27, ano LX, 1942, p. 19-21. 4 Leia-se COMPROMISSO da Misericórdia de Lisboa..., p. 9. 
vido na Mesa nos dois anos anteriores. Depois de acabado o escrutínio, os votos ficavam fechados "no nicho do Crucifixo" e o escrutínio só se efectuava no dia seguinte.

A escolha destes confrades era fundamental e era nesta eleição que as famílias poderosas jogavam muitos dos seus trunfos para acederem aos cargos de poder. Afinal, eram os eleitores que escolhiam os órgãos directivos da Santa Casa, porque se tratava de uma eleição indirecta. As Misericórdias eram normalmente as confrarias mais importantes em termos locais e estavam dominadas pelas elites da terra, que circulavam entre a Câmara e a Misericórdia em simultâneo ou em alternância.

No dia seguinte, depois de celebrada a missa, abriam-se as pautas e chamavam-se os escolhidos para darem continuidade ao processo eleitoral. Aos pares (um irmão nobre e outro oficial), procediam a escolha dos mesários. Os eleitores não podiam votar em irmãos que tivessem servido nos três anos precedentes, nem em si próprios. Concluído o acto, abriam-se as pautas e anunciava-se a constituição da nova Mesa.

Os actos eleitorais transformavam-se em momentos de grande significado e importância para estas instituições. Os interesses eram muitos, porque as Misericórdias eram ricas e prestigiadas, possibilitavam tráfico de influências e poder e eram permeáveis a redes de interesses.

No dia de Santa Isabel, as Misericórdias realizavam ainda uma procissão e algumas tinham também a prática de distribuir esmolas aos pobres.

A procissão era muito concorrida pelas gentes da terra que faziam uma pausa nos trabalhos quotidianos e se deixavam guiar pelos "repiques festivos" que anunciavam a festa e davam lugar à catarse ${ }^{5}$. A festa transformava-se num acontecimento aglutinador, que integrava elementos novos, um ponto de reencontro da comunidade, de familiares, de amigos, de gente que participava activamente, ou que simplesmente "via passar a procissão", fornecendo consistência à comunidade religiosa e constituindo um lugar de memória ${ }^{6}$.

5 Acerca da importância da festa no quotidiano das populações setecentistas consulte-se SOARES, Ivone da Paz. Sociabilidade Feminina. Enquadramento religioso no quotidiano da sociedade bracarense setecentista. Braga: Universidade do Minho, 1997, p. 120-122. Dissertação de mestrado. Policopiada.

6 José da Silva Lima fornece uma importante reflexão sobre a festa, enquanto elemento de sociabilização e de integração. Veja-se LIMA, José da Silva. Festas. In: AZEVEDO, Carlos Moreira, dir. Dicionário de História Religiosa. Lisboa: Círculo de Leitores, 2000, p. 251-253. 
Na procissão da festa de Santa Isabel participava igualmente a Câmara local. Em Melgaço, a Câmara vinha "asestir a festa da Besitação na Igreja desta Santa Casa da Misericordia acompanhando no fim a Prossição á qual bem todas as cruzes e povo do termo por ser huma das Prosiçoins Reaes a que tem obrigação de ir" ". Em Vila Viçosa, o anúncio da procissão efectuava-se "da janela da Camara para baixo" e o desfile contava também com a representação camarária8.

Como se tratava de um momento alto de celebração destas confrarias, em muitas Misericórdias associava-se a festa da padroeira aos pobres e distribuíam-se-lhes esmolas 9 . A Misericórdia de Valença enviava esmolas aos encarcerados no aljube da praça e beneficiava muitos pobres neste dia. Em 1769, gastou 9.350 réis com as esmolas enviadas às casas dos pobres $\mathrm{e}$ 6.350 réis com as que distribuiu à sua porta. Só nesta festa despendeu mais do que nas esmolas que ofereceu ao longo do ano. Nestas ofertas gastou, nesse ano, 10.900 réis $^{10}$.

Também na Santa Casa de Melgaço se escolheu este dia para entregar esmolas aos mais necessitados. Os pobres deviam efectuar uma petição à Mesa e aguardar provimento. A associação de pobres à festa da instituição era um acto carregado de simbolismo, que conferia visibilidade à principal função destas confrarias - a prática das obras de misericórdia - e associava os pobres, ainda que por momentos, a uma das realizações mais importantes destas instituições.

Nesta Misericórdia, era ainda costume o provedor pagar um jantar aos mesários e aos irmãos da Junta. Esta prática alargava-se ainda ao domingo de Passos e à quinta-feira das Endoenças ${ }^{11}$. Não era freqüente os

7 Para esta procissão leia-se ESTEVES, Augusto César. Santa Casa de Melgaço. Melgaço: Santa Casa da Misericórdia de Melgaço, 1957, p. 35-36.

8 A propósito da festa de Santa Isabel na Misericórdia de Vila Viçosa consulte-se ARAÚJO, Maria Marta Lobo de. Dar aos pobres e emprestar a Deus: as Misericórdias de Vila Viçosa e Ponte de Lima. Barcelos: Santa Casa da Misericórdia de Vila Viçosa; Santa Casa da Misericórdia de Ponte de Lima, 2000, p. 90.

9 Esta era uma prática já verificada em algumas confrarias medievais. Consulte-se MARQUES, José. Os pergaminhos da Confraria de S. João do Souto da cidade de Braga (1186-1545). In Bracara Augusta, v. XXXVI, n. 81-82, 1982, p. 85; FONSECA, Jorge. Para a história do associativismo no Alentejo medieval A Confraria e albergaria do Espírito Santo do Vimieiro. In: A cidade de Évora II série, 1998-1999, p. 38. 10 Arquivo da Santa Casa da Misericórdia de Valença (doravante ASCMV), Livro que ha de servir para nelle se carregar o produto das sisas sobnegadas desta vila e seu termo para se despenderem nas obras da Santa Caza, fls. 12v. e 20.

11 ESTEVES, Augusto César. Santa Casa de Melgaço..., p. 74-75. 
provedores custearem tantos jantares, tanto mais que exigia condições financeiras sólidas para arcar com estas despesas. Contudo, o facto de Melgaço ser uma vila fronteiriça pequena, onde as oportunidades de convivência não abundariam, teria contribuído para a Santa Casa, pela mão do provedor, oferecer aos seus corpos gerentes estes momentos de confraternização.

Foi precisamente por causa dos elevados custos e dos trabalhos que estes jantares exigiam que os mesmos foram desaparecendo, ao longo dos séculos XVII e XVIII. Os provedores queixavam-se dos grandes gastos e recusavam aceitar o cargo, devido às exigências que se lhes colocavam.

Contudo, se o acto eleitoral servia de momento de união dos irmãos e até de integração de novos membros, proporcionando uma ocasião de convívio entre nobres e oficiais, serviu também para exteriorizar descontentamentos, exibir ânimos exaltados e ocasionar distúrbios, demonstrando que a conflituosidade estava também presente nestas confrarias e podia eclodir a qualquer momento.

O século XVIII foi problemático para as Misericórdias, que se viram a braços com questões de vária ordem e que contribuíram para o seu descrédito: falta de irmãos, sobretudo de nobres; ascensão de homens menos "qualificados"; dificuldades nas cobranças de foros, de rendas e do crédito; diminuição de legados; perda, em vários casos, do monopólio do uso da tumba; receitas minguadas; crescente envolvimento em processos jurídicos e perturbação nos momentos em que se escolhiam os corpos gerentes ${ }^{12}$. Malgrado a difícil conjuntura em que se encontravam, teimavam em realizar festas pomposas, despendendo com elas muito do que tinham, em prejuízo da caridade aos pobres. Os actos eleitorais tornaram-se no barómetro da credibilidade destas instituições.

Na eleição de 1724 da Santa Casa de Montemor-o-Velho, eclodiu um conflito provocado pelo padre Francisco de Pina de Melo, que se "aclamara provedor", depois do acto estar terminado e do colégio eleitoral ter proclamado outro irmão vencedor. $\mathrm{O}$ acto parecia ter decorrido com toda a

12 Sobre a situação das Misericórdias no século XVIII consulte-se LOPES, Maria Antónia. As Misericórdias de D. José ao final do século XX. In: PAIVA, José Pedro (Coord.). Portugaliae Monumento Misericordiarum. Lisboa: Centro de Estudos de História Religiosa; União das Misericórdias Portuguesas, 2002 , p. 80 
normalidade e nada faria supor semelhante atitude. $\mathrm{O}$ assunto subiu ao rei e o referido sacerdote acabou por ser riscado da confraria ${ }^{13}$.

Em Vila Viçosa, o assunto das eleições foi também presente ao monarca em 1754, devido ao suborno a que esteve sujeito o escrutínio nesse ano. Os confrades informaram o rei do procedimento de um grupo de irmãos que, antes da votação, distribuíram papéis com os nomes dos eleitores que deviam escolher. $\mathrm{O}$ intento foi conseguido e escolhido para provedor um homem de negócios e para escrivão um outro que nem sequer pertencia à confraria. Depois de muita polémica e da Mesa se recusar a dar posse aos eleitos, o monarca ordenou a repetição do acto eleitoral, repondo-se a ordem e cumprindo-se o compromisso ${ }^{14}$.

\section{A Quaresma, as procissões, os jantares e as esmolas aos pobres}

Para além da festa de Santa Isabel, as Misericórdias comemoravam outros dias festivos do calendário litúrgico, investindo particularmente nos Passos e na semana santa. As confrarias passaram no pós-Trento a desempenhar um papel muito importante na organização social da esfera religio$\mathrm{sa}^{15}$.

O domingo de Passos era celebrado com uma missa, um sermão e uma procissão. Em Monção, era a Santa Casa quem pagava a festa dos

13 Para o sucedido na Misericórdia de Montemor-o-Velho veja-se SILVA, Mário José Costa da. A Santa Casa da Misericórdia de Montemor-o-Velho. Espaço de sociabilidade, poder e conflito (15461803). Figueira da Foz: Câmara Municipal de Montemor-o-Velho, 1999. p. 126. A propósito das dificuldades eleitorais surgidas na Praia da Vitória leia-se MOTA, Valdemar. Misericórdia da Praia da Vitória: memória histórica, 1498-1998. Praia da Vitória: Santa Casa da Misericórdia da Praia da Vitória, 1998. p. 48. Também na Misericórdia de Ponte da Barca se sentiram dificuldades semelhantes. Arquivo da Santa Casa da Misericórdia de Ponte da Barca (doravante ASCMPB), Livro das emleições desta santa caza da Mizericordia da villa da Ponte da Barca 1689-1718, n. 18, fls. 30-31.

14 Para o sucedido em Vila Viçosa confira-se ARAÚJO, Maria Marta Lobo de. Dar aos pobres e emprestar a Deus..., p. 100-101.

15 Leia-se ARAÚJO, Ana Cristina. Corpos sociais, ritos e serviços religiosos numa comunidade rural. As confrarias de Gouveia na Época Moderna. In: Revista Portuguesa de História, tomo XXXV. Coimbra: Faculdade de Letras da Universidade de Coimbra, 2001-2002, p. 274. 
Passos. Em 1746, os confrades reunidos em cabido "acordarão que se fizessem os passos por conta da Casa de sorte que os irmãos concorrerão com a factura delles na forma costumada fazendosse com os coadros da Casa e seus altares limpos e a despeza que nisto fizerem paga a Casa"16.

Nesta Misericórdia exigiam-se, em 1776, "pregadores capazes e de boa nota”, fazendo-se alusão à importância do momento e à representação da confraria na vila. A Santa Casa de Monção colocava particular empenho na celebração dos Passos. Os confrades reuniam-se com antecedência para organizar com minúcia a sua realização. Encomendava-se o sermão aos religiosos mais reputados da vila, alugavam-se as figuras em Valença, ajustavase a feitura das "capelas" com um carpinteiro da terra, encomendava-se a música em Braga ou mesmo em Tui (Galiza) e recordava-se o itinerário por onde desfilava o cortejo. Em 1788, os confrades de Monção "haviam por dada a musica dos Passos com as obrigações costumadas ao mestre da Solfa Gonçalo José de Moinhos pelo preço de des mil reis como se ajustou em outro anno com a condição de que não apresentando baixonista de Tui para a mesma função ficava sem efeito este ajuste" ${ }^{17}$.

A procissão dos Passos integrava figuras alusivas que invocavam santos, sendo normalmente as crianças que lhes davam corpo. A Misericórdia de Melgaço distribuía doces "aos anjos" e aos sacerdotes no final da procissão, tendo gasto nesta pequena merenda 3.455 réis, em $1723^{18}$. Para além destas figuras eram colocadas outras, não humanas, ao longo do itinerário, que representavam igualmente figuras bíblicas ${ }^{19}$.

Na Misericórdia de Monção, a festa dos Passos suplantava a de quinta e sexta-feira santa. Os confrades não estavam estatutariamente obrigados a participarem nesta cerimónia, mas eram muitos os que marcavam presença nesta solenidade.

16 Arquivo da Santa Casa da Misericórdia de Monção (doravante ASCMM), Livro que ha de servir para os acordãos e Enlleiçoens desta Santa Caza 1710-1774, n. 11, fl. 105.

17 ASCMM, Livro que ha de servir dos acordons desta Santa Miziricordia da villa de Monçon 1774-1815, n. 12, fl. 79.

18 Arquivo da Santa Casa da Misericórdia de Melgaço (doravante ASCMMço), Livro de receita e despesa 1717-1749, fl. 47.

19 Em 1746, a Santa Casa gastou oito colmeiros para encher estas figuras. ASCMMço, Livro de receita e despeza $1717-1749$, fl. $300 \mathrm{v}$. 
Contudo, o mais comum era que as festividades da semana santa fossem mais grandiosas. Era na quinta e sexta-feira que se realizavam as maiores procissões.

A semana santa era celebrada em todas as Misericórdias. Período de reflexão e arrependimento, originava momentos de grande religiosidade, claramente assumidos por estas confrarias. Os últimos dias da semana eram marcados por muitas cerimónias litúrgicas e na quinta e sexta-feira realizavam-se dois grandes desfiles processionais. Estes cortejos eram assinalados por manifestações de grande devoção religiosa que congregavam as populações locais e serviam de pretexto para estas se juntarem, observarem e/ou participarem nas cerimónias ${ }^{20}$.

A procissão de quinta-feira das Endoenças obrigava a presença de toda a irmandade. Era mais uma das ocasiões em que os irmãos se juntavam para darem cumprimento a uma iniciativa da instituição. O desfile saía de tarde e só terminava de noite, prolongando-se em algumas Misericórdias até muito tarde. Cumpria um itinerário previamente estabelecido, visitando algumas igrejas da terra, onde muitos populares o esperavam. Ou seja, para além dos participantes que o integravam desde o início, o cortejo ia engrossando à medida que passava por outros templos. Era ainda presenciado por muitos populares que se distribuíam ao longo das artérias por onde desfilava. A procissão transformava-se numa ocasião de encontro entre irmãos, sacerdotes e populares. Para além da gente da terra, acorria a esta procissão muita população das vizinhanças. Na Quaresma, o povo enchia as igrejas, ouvindo missa e assistindo a outros actos religiosos. As igrejas constituíam locais de sociabilidade para os crentes, os quais acorriam às cerimónias religiosas com grande fervor ${ }^{21}$.

A organização desta procissão era da responsabilidade das Misericórdias. Sabendo da importância destas ocasiões, as Santas Casas efectuavam um grande investimento. As Misericórdias cuidavam particular-

20 Sobre a procissão de quinta-feira santa na Misericórdia do Funchal veja-se JARDIM, Maria Dina dos Ramos. A Santa Casa da Misericórdia do Funchal - século XVIII. Coimbra: Centro de Estudos de História do Atlântico; Secretaria Regional do Turismo e Cultura, 1996, p. 170.

21 Leia-se LOUSADA, Maria Alexandra. Espaço urbano, sociabilidades e confrarias. Lisboa nos finais do Antigo Regime. In: COLÓQUIO INTERNACIONAL PIEDADE POPULAR - SOCIABILIDADES E REPRESENTAÇÕES. Actas... Lisboa: Terramar, 1999, p. 540-542. 
mente dos momentos em que saíam à rua e se expunham à observação e julgamento da comunidade. Da sua capacidade de os organizarem dependia a ascensão ou diminuição da sua credibilidade e a recepção de mais ou menos heranças. Estes momentos também serviam para ajudar a decidir os potenciais benfeitores da entrega da sua fortuna a estas instituições para legados pios e bens da sua alma.

Como se tratava de uma das mais importantes manifestações de identidade e reforço de poder das Misericórdias, estas confrarias não se poupavam a esforços para garantir a sua solenização e exibirem a sua capacidade organizadora ${ }^{22}$.

A preparação do cortejo efectuava-se com minúcia. A Mesa reunia tendo, em muitas Misericórdias, como ponto único de agenda a montagem da procissão. Os irmãos decidiam o número de velas necessário, mandavam decorar o interior da igreja, consertar alfaias religiosas, estipulavam o azeite preciso para os novelos, o vinho para os penitentes e mandavam varrer o caminho por onde esta haveria de passar ${ }^{23}$. Em muitas Misericórdias era ainda ocasião para se limpar a casa, em especial o pátio, caiar a frontaria e comprar mobília nova. Tudo para que irmãos e populares admirassem a instituição e a festa fosse ainda mais dignificada e aumentasse o reconhecimento social e se reconhecesse a capacidade da confraria criar e desenvolver oportunidades de sociabilidade ${ }^{24}$. Os seus membros lucravam com esse prestígio e usufruíam do intenso convívio que se proporcionava nestas ocasiões.

22 Veja-se PAIVA, José Pedro. "Etiqueta e cerimónias públicas na esfera da Igreja (séculos XVII-XVIII)”. In: Cultura e Sociabilidades na América Portuguesa. São Paulo: Hucitec, 2001, p. 75-94 23 Para um melhor conhecimento da preparação da procissão de quinta-feira das Endoenças em Esposende leia-se COSTA, M. M. da Silva. A Misericórdia de Esposende e a Santa Casa: apontamentos históricos. Esposende: Santa Casa da Misericórdia de Esposende, 1988, p. 31-38. Para a Misericórdia da Lousã veja-se LEMOS, Eugénio de. A Santa Casa da Misericórdia da vila da Lousã - resenha histórica. Lousã: Santa Casa da Misericórdia da Lousã, 1966. p. 180-181; para o Porto leia-se SOUSA, Ivo Carneiro de. A procissão de quinta-feira santa da confraria da Misericórdia do Porto [1646]. O Tripeiro, v. 7, n. 14 1995, p. 110-114. Sobre a procissão de quinta-feira santa na Misericórdia da Póvoa de Varzim confira-se DIONÍSIO, Paula Carolina Ramos. A Santa Casa da Misericórdia da Póvoa de Varzim. Assistência e caridade numa vila piscatória (1756-1806). Porto: Faculdade de Letras, 2001, p. 143-147. Dissertação de mestrado. Policopiada.

24 Pode-se aprofundar esta temática em PENTEADO, Pedro. Confrarias. In: AZEVEDO, Carlos Moreira (Dir.). História Religiosa de Portugal, v. 2, Lisboa: Círculo de Leitores, 2000, p 323-330. 
Embora toda a irmandade devesse estar presente, os lugares mais importantes eram preenchidos pelos irmãos que ocupavam ou tinham desempenhado cargos na confraria. Eram eles que transportavam as varas, as insígnias, a bandeira e as tochas. A procissão terminava com o pálio e o crucifixo carregados, respectivamente, pelo provedor do ano anterior e pelo actual $^{25}$. Era evidente o respeito pela hierarquia e a disciplina imposta cumpria vários objectivos: por um lado, conferia capacidade de organizar o desfile à confraria e, por outro, evidenciava a operacionalidade da instituição ao agregar à sua volta todos os devotos que desejavam participar nesta cerimónia.

Esta procissão integrava ainda penitentes que desfilavam, autoflagelando-se. As práticas de penitência através da flagelação eram formas de exteriorizar reverência a Deus, tinham sido exercitadas na Idade Média com fervor e tiveram nos franciscanos e nos dominicanos fortes agentes da sua divulgação $0^{26}$.

Aos penitentes era, no final da procissão, distribuído vinagre ou vinho para curar as feridas e oferecida uma pequena refeição. A composição deste beberete nem sempre foi descrita, mas, em 1808, a Misericórdia dos Arcos de Valdevez gastou dois mil réis em "des caixas de doce para a procissão de quinta feira santa" ${ }^{27}$. Em algumas Misericórdias era constituído por marmelada, confeitos e cidrão ${ }^{28}$.

Estas confrarias esperavam a presença de todos os seus membros e aguardavam comportamentos adequados e que as dignificassem. Porém, nem sempre assim acontecia, porque os irmãos ou não compareciam, ou apresentavam-se sem balandrau ou, pior ainda, escolhiam a ocasião para manifestar o seu desagrado com a instituição. As confrarias davam-lhes a

25 A propósito desta procissão na Misericórdia de Castelo Branco consulte-se SILVA, H. Castro e. A Misericórdia de Castelo Branco (apontamentos históricos). Castelo Branco: Santa Casa da Misericórdia de Castelo Branco, 1958, p. 108-111.

26 Leia-se GOUVEIA, António Camões. Procissões. In: AZEVEDO, Carlos Moreira (Dir.). Dicionário de História Religiosa. Lisboa: Círculo de Leitores, 2001, p. 69.

27 Arquivo da Santa Casa da Misericórdia dos Arcos de Valdevez (doravante ASCMAV), Livro de receita e despeza 1801-1812, fl. 36.

28 Estes eram os elementos que integravam a refeição servida pela Santa Casa do Porto ao penitentes. Leia-se BASTO, A. de Magalhães. História da Santa Casa da Misericórdia do Porto. v. 1, 2. ed. Porto: Santa Casa da Misericórdia do Porto, 1997, p. 491. 
oportunidade de justificar os seus actos, mas quando não o faziam ou as razões invocadas não satisfaziam a instituição, eram riscados.

Em 1734, o padre João de Caldas e "os seus filhos naturais", os padres António de Freitas, Manuel Lourenço e Manuel Velho Soares, irmãos da Misericórdia de Monção,

(...) perturvando o piedoso e louvavel acto da procissão [na noite de quinta feira maior] com cançoens destemperadas no choro da Igreja Matriz em o pobrio da Irmandade e Mestre da musica que hia na dita procissão cantando devotamente (...) sendo mais sensivel aquela perturvação e desatenção por estar o Senhor exposto (...) dando ocasião a um disturbio e danno prejudicial em termos de sua execução sendo o dito referido facto com animo de injuria com o pobrio.

Mas esta não foi a única anomalia desta procissão. O irmão Pedro Lourenço de Almeida tomou o partido dos anteriores e proferiu "palavras menos atentas" 29 . Depois de analisado o sucedido, estes confrades foram riscados da irmandade.

Nem sempre os irmãos tinham uma atitude tão provocadora. Houve situações em que foram mais contidos, mas igualmente indisciplinados: não se apresentavam com o balandrau, não queriam carregar o andor, os irmãos sacerdotes negavam-se a cantar, desfilando em silêncio, não desejavam empunhar a tocha e recusavam-se a pedir durante a procissão.

Para além da oportunidade que a procissão criava aos irmãos de se juntarem e conviverem entre si e com os outros participantes, a quinta-feira era também o dia de muitas Misericórdias celebrarem o lava-pés. O provedor reproduzindo a cena bíblica, lavava os pés a 12 pobres, a quem posteriormente oferecia um jantar e distribuía alguns géneros alimentares e roupa ou dinheiro ${ }^{30}$. Oferecia ainda um jantar aos presos. O provedor sentava à sua mesa os 12 pobres com quem compartilhava a refeição.

29 ASCMM, Livro que ha de servir para os acordãos e Enlleiçoens..., fls. 86v.-87.

30 Leia-se ARAÚJO, Maria Marta Lobo de. Festas e rituais de caridade das Misericórdias. In: COLÓQUIO INTERNACIONAL PIEDADE POPULAR... Actas, p. 501-521; SÁ, Isabel dos Guimarães. As Misericórdias Portuguesas de D. Manuel I a Pombal. Lisboa: Livros Horizonte, 2001, p. 93. 
Na Idade Moderna, a mesa tinha-se tornado num local de sociabilidade e de inserção social, originando várias manifestações ritualizadas: a ocupação dos lugares, a distribuição do pão e o agradecimento a Deus pela refeição ${ }^{31}$. Como era muito raro os ricos se sentarem à mesa dos pobres, estes momentos revestiam-se de particular significado e estavam carregados de simbolismo.

Estes rituais alimentares, tão criticados pelas Igrejas católica e protestante ao longo da Idade Moderna, estavam já implantados na Idade Média, onde muitas confrarias implementaram refeições periódicas entre os confrades ou entre estes e elementos exteriores a estas instituições, como eram, por exemplo, os pobres ${ }^{32}$. Estas manifestações que reuniam à mesma mesa confrades e pobres, constituíam importantes formas de socialibilade ${ }^{33}$.

Estes jantares fortaleciam a coesão da instituição e promoviam espaços de convívio e de partilha entre os participantes.

A refeição servida aos presos era sempre abundante e melhorada em qualidade e quantidade, ficando normalmente comida para os dias seguintes. Existiam Santas Casas que repetiam estes jantares no dia de Páscoa e no dia dos Fiéis-Defuntos ${ }^{34}$. Em algumas destas confrarias, estas refeições atingiam tal qualidade que incluíam música ${ }^{35}$.

Em Vila Viçosa, os encarcerados não beneficiavam apenas do jantar de quinta-feira santa, oferecido pela Santa Casa local. Durante os restantes dias da semana santa eram presenteados com jantares oferecidos pelas ordens religiosas da vila ${ }^{36}$.

31 Para esta temática veja-se THELAMOU, Françoise. Sociabilité et conduites alimentaires. In: $\quad L a$ sociabilité à table. Commensalité et convivialité à travers les âges. Rouen: Université de Rouen, 1993. p. 9-15; SARTI, Rafaella. Casa e família. Habita, comer e vestir na Europa Moderna. Lisboa: Editorial Estampa, 2001, p. 249

32 Sobre os momentos de sociabilidade criados pelas confrarias medievais leia-se BEIRANTE, Maria Ângela. Confrarias Medievais Portuguesas. Lisboa: Ed. da autora, 1990, p. 31-38.

33 Veja-se BEIRANTE, Maria Ângela. Ritos alimentares em algumas confrarias portuguesas medievais. In: COLÓQUIO INTERNACIONAL PIEDADE POPULAR... Actas, p. 559.

34 Acrescente-se que as Misericórdias distribuíam regularmente comida (quartas e domingos) aos presos.

35 Para o que se passava na Misericórdia de Tavira consulte-se ANICA, Arnaldo Casimiro. $O$ hospital do Espírito Santo da cidade de Tavira (da fundação à actualidade - notas). Tavira: [s.n.], 1983, p. 56.

36 Confira-se ARAÚJO, Maria Marta Lobo de. Festas e rituais de caridade nas Misericórdias. In: COLÓQUIO INTERNACIONAL PIEDADE POPULAR... Actas, p. 506-507. 
Estas refeições eram complementadas em muitas Misericórdias com entregas massivas de esmolas aos pobres ${ }^{37}$. A Misericórdia de Vila Viçosa entregava milhares de esmolas aos pobres no pátio da sua casa, contemplando os pobres da vila e dos arredores. Eram os confrades que as distribuíam, criando momentos de convívio entre pobres e ricos, ainda que por um curto espaço de tempo. Estas oportunidades possibilitavam uma maior proximidade e conferiam dignidade e prestígio aos que simulavam humilda$\mathrm{de}^{38}$.

Mas a quinta-feira não era o único dia de reunião de pobres com ricos. Na Misericórdia de Vila Viçosa, o sábado de Aleluia era marcado por nova distribuição de esmolas aos pobres, agora em número ainda superior. Para além das ofertas que efectuavam aos pobres no pátio, os irmãos iam à casa dos mais desfavorecidos entregar a esmola. Esta oferta era distribuída de noite e abrangia muitos pobres envergonhados.

$\mathrm{Na}$ semana santa estreitavam-se ainda laços de fraternidade com os assalariados. Muitas Misericórdias agraciavam os seus assalariados com as "propinas", incluindo-os nas listas dos que proviam e facultando-lhes a possibilidade de integrarem estas manifestações de convivialidade.

\section{Os enterros}

Os elos de solidariedade que as confrarias desenvolviam em vida perpetuavam-se na morte ${ }^{39}$. A solidariedade entre vivos e mortos representava na dimensão espiritual o patamar mais importante da sociabilidade

37 Acerca das esmolas distribuídas aos pobres pela Misericórdia de Macau na semana santa e no dia de santa Isabel veja-se SÁ, Isabel dos Guimarães. Ganhos da terra e ganhos do mar: caridade e comércio na Misericórdia de Macau (séculos XVII e XVIII). Ler História, n. 44, 2003, p. 54-56. Para a Misericórdia de Braga consulte-se CASTRO, Maria de Fátima. A Irmandade e Santa Casa da Misericórdia de Braga, Braga: Santa Casa e Autora, 2001. p. 199, nota de rodapé 106. p. $131-132$

38 MUIR, Edward. Ritual in Early Modern Europe. Cambridge: University Press, 1997,

39 Consulte-se ARAÚJO, Ana Cristina. Corpos sociais, ritos e serviços religiosos numa comunidade rural. As confrarias de Gouveia na Época Moderna. In: Revista Portuguesa de História, n. 35, p. 174. 
grupa ${ }^{40}$. A assistência à alma era uma vertente fundamental em todas as confrarias e também nas Misericórdias. Ela seria uma das razões que mais pesava no momento da decisão de integrar uma destas associações. Os que podiam, inscreviam-se em mais do que uma irmandade para usufruírem de mais benefícios espirituais ${ }^{41}$.

Enterrar os mortos era uma das obras de misericórdia corporais que as Santas Casas levavam muito a sério. Acompanhavam gratuitamente à sepultura e enterravam os seus próprios irmãos, devendo as confrarias apresentarem-se em corpo nestes momentos. O defunto devia ser acompanhado por toda a irmandade, ocasião que servia para lhe prestar a última homenagem, mas também solidariedade no momento da passagem. Sepultavam também gratuitamente a mulher e os filhos menores dos confrades. Enterravam ainda todos os que podiam pagar o preço do serviço que a confraria efectuava e que incluía a tumba, a bandeira, a cera e as toalhas. A sepultura era paga à instituição onde esta se localizava. Mas as Misericórdias sepultavam gratuitamente todos os que sendo pobres não dispunham de meios para o enterro. Procurava-os na cadeia, na rua, nos alpendres, em palheiros, em suas casas e nos poços ou nos rios, onde tivessem morrido afogados ${ }^{42}$. Este ritual de solidariedade estava ligado à noção de que a "boa morte" nunca se materializava num acto solitário.

O medo que acompanhava os homens quando a morte se avizinhava e a vida se acabava tornava-os pios e aproximava-os dos santos, da Virgem Maria e de Cristo, a quem solicitavam que intercedessem junto de Deus a seu favor.

As Misericórdias adequavam os enterros ao serviço que lhe era solicitado. Os seus membros tinham um tratamento diferenciado. Desde logo pela forma como o seu óbito era comunicado à irmandade e em particular a toda a comunidade. O sino tocava toques diferentes dos costumados e

40 Veja-se ENES, Maria Fernandes. A confraria de São Pedro Gonçalves em Ponta Delgada no séc. XIX. Espaço de sociabilidade. In: COLÓQUIO INTERNACIONAL PIEDADE POPULAR... Actas, p. 598

41 Para este assunto leia-se GOMES, Paula Alexandra de Carvalho Sobral. Oficiais e confrades em Braga no tempo de Pombal. (Contributos para o estudo do movimento e organização confraternal bracarense no século XVIII). Braga: Universidade do Minho, 2002. p. 128. Dissertação de mestrado. Policopiada.

42 A Misericórdia de Melgaço tinha como obrigação enterrar todos os pobres que tinham morrido afogados. ASCMMço, Livro do tombo de 1790, fl. 31v. 
que a comunidade identificava. Depois era ordenado que corressem campainhas manuais pelas principais artérias da vila ou da cidade. Os irmãos eram enterrados numa tumba melhor, acompanhados com uma bandeira que lhes estava especialmente destinada e os mesários apresentavam-se com todas as insígnias próprias destas ocasiões ${ }^{43}$. Tratava-se de um cerimonial aparatoso e formal. O compromisso de 1618 da Misericórdia de Lisboa determinava ainda que os confrades rezassem 14 Padre Nossos e 14 Ave Marias, enquanto iam ao lado do seu irmão ${ }^{44}$. O acompanhamento da irmandade estava garantido e os faltosos eram sancionados, podendo a pena ditar a sua expulsão. Contudo, se o defunto integrasse outras confrarias, contava igualmente com a solidariedade de outros irmãos que se mantinham a seu lado neste momento tão difícil. Mesmo não sendo seu membro, podia ainda recrutar outras confrarias para o cortejo fúnebre, mediante pagamento do serviço.

Era, pois, freqüente os homens e as mulheres de posses terem nos seus funerais várias irmandades que integravam ou que convocaram para esta ocasião $0^{45}$.

Pertencer a uma confraria significava adquirir a acção protectora da irmandade em vida, um funeral assistido e alguns sufrágios que estas instituições mandavam celebrar pelos irmãos defuntos ${ }^{46}$. Estes serviços assumiam tal relevo que muitos homens e mulheres filiavam-se em várias destas instituições. A adesão estava marcada pelos insistentes apelos que a Igreja tridentina não se cansava de efectuar a todos os seus fregueses, encaminhando-os para os altares ${ }^{47}$.

A assistência aos defuntos pelas Misericórdias obrigava em algumas situações a dispêndio de tempo e a efectuar deslocações. As Santas

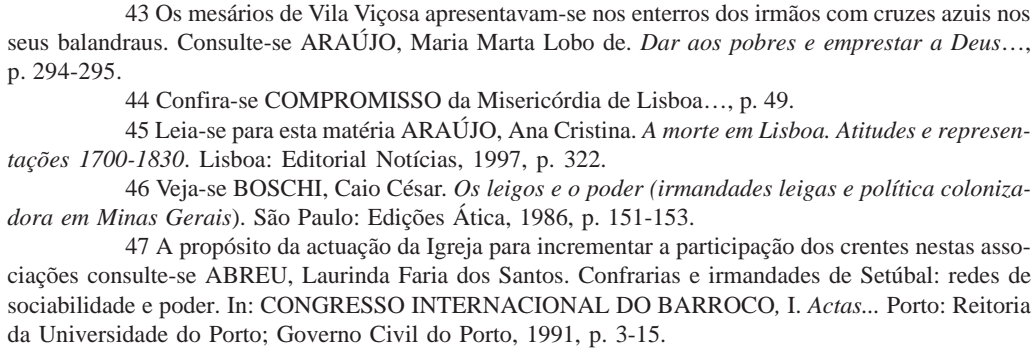


Casas tinham normalmente uma área circunscrita de actuação e um tarifário estabelecido para este serviço, mas freqüentemente cediam a pressões e enterravam defuntos fora do limite estabelecido. Para mais facilmente captar a presença dos confrades nos funerais, a Misericórdia de Melgaço pagava, em 1790, uma refeição aos confrades que iam acompanhar os enterros às freguesias mais distantes da vila, quer fossem de irmãos ou não. Dava "1.600 reis para a refeição ou como regularmente chamam beberete dos irmãos", ou em sua substituição dois arráteis de bacalhau ${ }^{48}$.

Tratava-se de uma medida de aliciamento, numa altura em que os confrades eram cada vez mais remissos a esta tarefa, que tinha por objectivo reconfortá-los e que originava um momento de partilha entre os irmãos.

Os confrades serviam-se do pretexto de estarem juntos e serem actos públicos para exteriorizarem o seu descontentamento e qualquer motivo servia, mesmo que se tratasse de uma cerimónia fúnebre. Em 1765, alguns confrades da Misericórdia de Porto de Mós aproveitaram a saída da irmandade a um enterro para descomporem os irmãos que nele participaram e prejudicar a imagem pública da instituição. Esta tomada de atitude prendia-se com uma queixa apresentada por alguns confrades ao rei contra outros irmãos que tinham ocupado cargos directivos na instituição e que, segundo os primeiros, tinham agido contra os interesses da confraria e em seu proveito próprio. Não contentes, os visados procuraram apoio no resto da irmandade, fazendo os irmãos assinar, sob coacção, um subscrito contra a queixa. Mesmo assim, não conseguiram que todos satisfizessem o pretendido.

Por isso,

(...) saindo a irmandade com a tumba para certo enterro de domingo, indo a irmandade incorporada e guiada por um irmão de primeira condição, o bacharel, Manuel de Deus Leal, levando a vara na falta do provedor e escrivão, na rua pública lhe saiu ao encontro Domingos António de Vasconcelos, que de presente serve de escrivão e sem vir com o vestido da irmandade arrebatou, atirou a vara da mão do dito irmão descompondo-o e repreendendo dando a mesma repreensão publicamente aos 
irmãos que iam na dita acção, o que muito se estranhou por ser em lugar público ${ }^{49}$.

Estes actos reprovados pelas confrarias punham à prova a solidariedade entre vivos e mortos, assim como "mediam e experimentavam os laços de sociabilidade" destas instituições ${ }^{50}$. Eram braços de ferro que se erguiam contra a coesão e a representação social da confraria numa luta da qual a instituição saía normalmente vitoriosa.

Em algumas situações, os confrades recusaram-se a pegar na tumba ou a carregar a bandeira ou a levar as tochas. Outros, num acto provocatório, compareciam com as insígnias de outras confrarias ou ordens religiosas, enfurecendo os corpos gerentes das Misericórdias ${ }^{51}$. No século XVIII, foram sobretudo as Ordens Terceiras que mais afrontaram as Misericórdias neste campo, levando a que muitos irmãos, que eram simultaneamente seus membros, envergassem as suas insígnias e não as da Misericórdia.

Estes momentos, plenos de simbolismo, eram geradores de sociabilidades que não coincidiam com as oportunidades de convívio surgidas no dia-a-dia. Obedeciam a um calendário distinto, combinavam outros grupos sociais e alargavam as redes de fraternidade e de convivialidade entre os homens. Era através do espírito de união que se desenvolvia o sentimento de pertença e se fortalecia a coesão destas "famílias de devotos" e de irmãos piedosos.

A pertença à confraria mais prestigiada da terra conferia-lhes prestígio e poder, ao mesmo tempo que abria portas para aceder a espaços de sociabilidade que de outra forma estavam vedados. Se por um lado isso era uma razão que motivava a adesão, contribuía simultaneamente para reforço

49 Arquivo da Casa de Bragança (doravante ACB), NNG, 1150, fls. 634-638.

50 A propósito dos conflitos que surgiam nestas ocasiões e da prova de fogo que constituíam contra a harmonia e a paz destas instituições leia-se ABREU, Laurinda Faria dos Santos. A Santa Casa da Misericórdia de Setúbal de 1500-1755: aspectos de sociabilidade e poder. Setúbal: Santa Casa da Misericórdia de Setúbal, 1990, p. 156-157.

51 Para os conflitos surgidos na Misericórdia de Guimarães aquando dos enterros consultese COSTA, Américo Fernando da Silva. A Santa Casa da Misericórdia de Guimarães (caridade e assistência no meio vimaranense dos séculos XVII e XVIII). Guimarães: Santa Casa da Misericórdia de Guimarães, 1999, p. 189-191. 
da identidade da instituição, aumentava a coesão do grupo, promovia a admiração e a estima da comunidade, ao mesmo tempo que fazia aumentar o orgulho de quem as integrava e desenvolvia relações interpessoais. Estes actos promovidos pelas Misericórdias e que proporcionavam momentos de sociabilidade eram planificados para as engrandecer e ocasionar maior poder e glória.

\section{Referências}

ABREU, Laurinda Faria dos Santos. Confrarias e irmandades de Setúbal: redes de sociabilidade e poder. In CONGRESSO INTERNACIONAL DO BARROCO, I. Actas. Porto: Reitoria da Universidade do Porto; Governo Civil do Porto, 1991, p. 3-15.

ABREU, Laurinda Faria dos Santos. A Santa Casa da Misericórdia de Setúbal de 1500-1755: aspectos de sociabilidade e poder. Setúbal: Santa Casa da Misericórdia de Setúbal, 1990.

ANICA, Arnaldo Casimiro. O hospital do Espírito Santo da cidade de Tavira (da fundação à actualidade - notas). Tavira: [s.n.], 1983.

ARAÚJO, Ana Cristina. A morte em Lisboa. Atitudes e representações 1700-1830. Lisboa: Editorial Notícias. 1997.

ARAÚJO, Ana Cristina. Corpos sociais, ritos e serviços religiosos numa comunidade rural. As confrarias de Gouveia na Época Moderna. In Revista Portuguesa de História, n. 35. Coimbra: Faculdade de Letras da Universidade de Coimbra, 20012002, p. 279-287.

ARAÚJO, Maria Marta Lobo de. Festas e rituais de caridade nas Misericórdias. In: COLÓQUIO INTERNACIONAL PIEDADE POPULAR - SOCIABILIDADES E REPRESENTAÇÕES. Actas. Lisboa: Terramar, 1999, p. 501-521.

ARAÚJO, Maria Marta Lobo de. Dar aos pobres e emprestar a Deus: as Misericórdias de Vila Viçosa e Ponte de Lima. Barcelos: Santa Casa da Misericórdia de Vila Viçosa; Santa Casa da Misericórdia de Ponte de Lima, 2000.

BASTO, A. de Magalhães. História da Santa Casa da Misericórdia do Porto. 1, 2. ed. Porto: Santa Casa da Misericórdia do Porto, 1997. 
BEIRANTE, Maria Ângela. Confrarias Medievais Portuguesas. Lisboa: Ed. da autora, 1990.

BEIRANTE, Maria Ângela. Ritos alimentares em algumas confrarias portuguesas medievais. In: COLÓQUIO INTERNACIONAL PIEDADE POPULAR - SOCIABILIDADES E REPRESENTAÇÕES. Actas... Lisboa: Terramar, 1999, p. 559-570.

BOSCHI, Caio César. Os leigos e o poder (irmandades leigas e política colonizadora em Minas Gerais). São Paulo: Edições Ática, 1986.

CASTRO, Maria de Fátima. A Irmandade e Santa Casa da Misericórdia de Braga. Braga: Santa Casa e Autora, 2001.

COMPROMISSO da Misericórdia de Lisboa. Lisboa: Pedro Craesbeeck, 1619.

CORREIA, Fernando da Silva. A Misericórdia de Lisboa. A Medicina Contemporânea, n. 27, ano LX, 1942, p. 19-21.

COSTA, Américo Fernando da Silva. A Santa Casa da Misericórdia de Guimarães (caridade e assistência no meio vimaranense dos séculos XVII e XVIII). Guimarães: Santa Casa da Misericórdia de Guimarães, 1999.

COSTA, M. M. da Silva. A Misericórdia de Esposende e a Santa Casa: apontamentos históricos. Esposende: Santa Casa da Misericórdia de Esposende, 1988.

DIONíSIO, Paula Carolina Ramos. A Santa Casa da Misericórdia da Póvoa de Varzim. Assistência e caridade numa vila piscatória (1756-1806). Porto: Faculdade de Letras, 2001, p. 143-147. Dissertação de mestrado. Policopiada.

ENES, Maria Fernandes. A confraria de São Pedro Gonçalves em Ponta Delgada no séc. XIX. Espaço de sociabilidade. In: COLÓQUIO INTERNACIONAL PIEDADE POPULAR - SOCIABILIDADES E REPRESENTAÇÕES. Actas... Lisboa: Terramar, 1999, p. 591-607.

ESTEVES, Augusto César. Santa Casa de Melgaço. Melgaço: Santa Casa da Misericórdia de Melgaço, 1957.

FONSECA, Jorge. Para a história do associativismo no Alentejo medieval. A Confraria e albergaria do Espírito Santo do Vimieiro. In: A cidade de Évora. II série, 19981999, p. 31-43.

GOMES, Paula Alexandra de Carvalho Sobral. Oficiais e confrades em Braga no tempo de Pombal. (Contributos para o estudo do movimento e organização confraternal bracarense no século XVIII). Braga: Universidade do Minho, 2002. Dissertação de mestrado. Policopiada. 
GOUVEIA, António Camões. Procissões. In: AZEVEDO, Carlos Moreira. (Dir.). Dicionário de História Religiosa. 2. Lisboa: Círculo de Leitores, 2001, p. 334-345.

JARDIM, Maria Dina dos Ramos. A Santa Casa da Misericórdia do Funchal século XVIII. Coimbra: Centro de Estudos de História do Atlântico; Secretaria Regional do Turismo e Cultura, 1996.

LEMOS, Eugénio de. A Santa Casa da Misericórdia da vila da Lousã - resenha histórica. Lousã: Santa Casa da Misericórdia da Lousã, 1966.

LIMA, José da Silva. Festas. In: AZEVEDO, Carlos Moreira. (Dir.). Dicionário de História Religiosa. Lisboa: Círculo de Leitores, 2000, p. 251-263.

LOPES, Maria Antónia. As Misericórdias de D. José ao final do século XX. In: PAIVA, José Pedro (Coord.). Portugaliae Monumenta Misericordiarum. Lisboa: Centro de Estudos de História Religiosa; União das Misericórdias Portuguesas, 2002, p. 79-117.

LOUSADA, Maria Alexandra. Espaço urbano, sociabilidades e confrarias. Lisboa nos finais do Antigo Regime. In: COLÓQUIO INTERNACIONAL PIEDADE POPULAR - SOCIABILIDADES E REPRESENTAÇÕES. Actas... Lisboa: Terramar, 1999, p. 537-558.

MARQUES, José. Os pergaminhos da Confraria de S. João do Souto da cidade de Braga (1186-1545). In: Bracara Augusta, v. XXXVI, n. 81-82, 1982, p. 71-103.

MESGRAVIS, Laima. A Santa Casa da Misericórdia de S. Paulo (1599?-1884). São Paulo: Conselho Estadual de Cultura, 1976.

MOTA, Valdemar. Misericórdia da Praia da Vitória: memória histórica, 1498-1998. Praia da Vitória: Santa Casa da Misericórdia da Praia da Vitória, 1998.

MUIR, Edward. Ritual in Early Modern Europe. Cambridge: University Press, 1997.

PENTEADO, Pedro. Confrarias. In: AZEVEDO, Carlos Moreira. (Dir.). História Religiosa de Portugal, v. 2, Lisboa: Círculo de Leitores, 2000, p. 322-334.

SÁ, Isabel dos Guimarães. As Misericórdias Portuguesas de D. Manuel I a Pombal. Lisboa: Livros Horizonte, 2001.

SÁ, Isabel dos Guimarães. Ganhos da terra e ganhos do mar: caridade e comércio na Misericórdia de Macau (séculos XVII e XVIII). Ler História, n. 44, 2003, p. 45-57.

SARTI, Rafaella. Casa e família. Habita, comer e vestir na Europa Moderna. Lisboa: Editorial Estampa, 2001. 